\title{
A Critical Introduction to Arts Behind Bars 8
}

\author{
Aylwyn Walsh, School of Performance and Cultural Industries, University of Leeds
}

https://doi.org/10.1093/acrefore/9780190264079.013.18

Published online: 26 September 2017

\section{Summary}

This article proposes a focus on some of the arguments in the field-what is "arts behind bars"? What are some of the intentions, and why would people do it? It also signals the range of practices that are to be found-from the development of needlework in male prisons through to participatory arts projects with young people in prisons to collaborative stage shows. Artists working in criminal justice have a wide range of intentions. For a few, there might be a frisson of the danger and caged energy behind bars that is stimulating to creativity and could add something to their own creative process. The model of art for prisoners-professional artists staging a show or doing an unplugged music event in a prison-can raise the profile of prisons and punishment. However, there are a great number of projects that move towards forms of art created with and by prisoners, thereby aligning them with a long history of social and participatory arts. Theoretically, then, the arts behind bars are informed by critical pedagogies as much as the specific disciplinary approaches. This model seeks to build critical consciousness and confidence in mastery as well as induction into the discipline of learning any skill for the purposes of liberating through knowledge. In arts behind bars, the knowledge base might include literacy outcomes, but the learning is often communal, and about creative self-expression.

The practitioners of arts behind bars have two driving intentions. Either they seek to engage more people with their art form and are willing to work in a range of contexts, or they are committed to social justice and hope to use the art form towards additional aims of generating understanding and redressing some of the inequalities experienced by prisoners. It is necessary to consider what new perspectives are offered to the subject of arts in criminal justice by thinking about how wider resources, culture, and artistic paradigms affect perceptions of the value of interventions. This highlights the need for awareness of those artists who choose to work in prisons of the moral and ethical questions raised by bringing art to the system.

Keywords: arts, arts education, arts for social change, desistance, reducing reoffending interventions, prison theater

Subjects: Crime, Media, and Popular Culture

You do not currently have access to this article

\section{Login}

Please login to access the full content.

\section{Subscribe}

Access to the full content requires a subscription 